\title{
Efeito do estresse pré-natal na regulação da inflamação alérgica pulmonar no modelo murino de asma experimental
}

\author{
Efecto del estrés prenatal en la regulación de la inflamación \\ alérgica pulmonar en el modelo murino de asma experimental
}

\section{Effect of prenatal stress in regulating pulmonary allergic inflammation in a murine model of experimental asthma}

\author{
Vagner Gonçalves Jr ${ }^{1 *}$; Ana Paula Ligeiro de Oliveira ${ }^{2 * *}$; Karin Kieling ${ }^{3 * *}$; \\ Natalia Andrea Cruz Ochoa ${ }^{* * * *}$; Julieta E Ochoa Amaya $5^{* * * * *}$; \\ Pablo Emilio Cruz-Casallas 6****** $^{* *{ }^{* *}}$ Maria Martha Bernardi $7^{* * * * * *}$
}

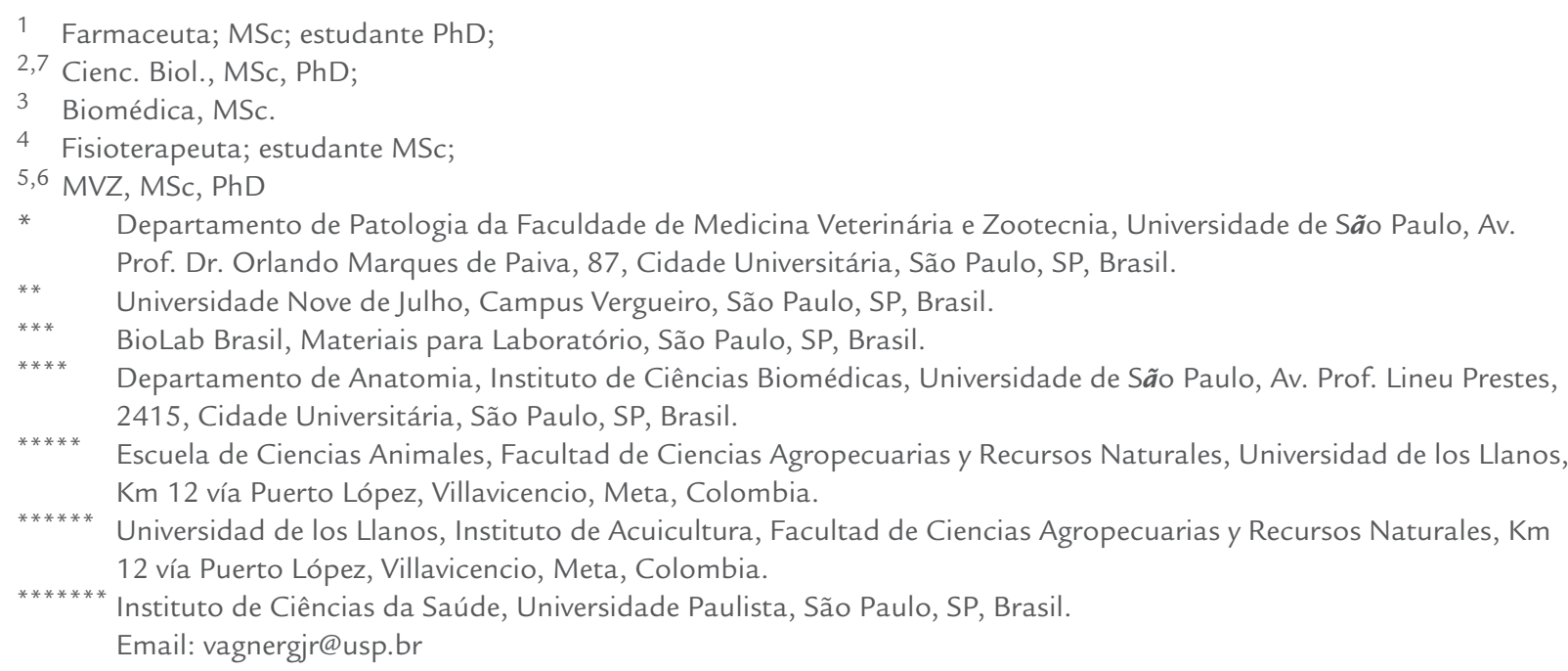

\section{Resumo}

Devido ao seu rápido crescimento, o feto é particularmente vulnerável a insultos e modificações no millieu hormonal. Este fato sugere que situações adversas experimentadas pela mãe grávida podem alterar o desenvolvimento e a saúde da prole, explicado principalmente pela permeabilidade da barreira placentária a diversos hormônios e substâncias. O objetivo deste trabalho foi estudar o efeito do estresse pré-natal na regulação da inflamação alérgica pulmonar, empregando o modelo murino de asma experimental. Para este propósito foram utilizadas camundongas virgens da linhagem Swiss, com 50 dias de idade. Foi empregado o modelo de choque nas patas para promover o estresse pré-natal e o modelo do "metrô de Nova 
lorque" para o estresse pós-natal. As fêmeas foram distribuídas em 4 grupos experimentais: CC: fêmeas não estressadas; CE: fêmeas estressadas pós-natalmente aos 60 dias de idade (PND60), EC: fêmeas nascidas de mães estressadas entre o dia 15 (GD15) e 18 de gestação (GD18); EE: fêmeas nascidas de mães estressadas entre o GD15 e GD18 e estressadas pós-natalmente aos PND60. A indução da inflamação alérgica pulmonar foi realizada através da sensibilização dos animais com solução de ovalbumina (OVA) $0,1 \mathrm{mg} \mathrm{Kg}^{-1}$ sc para avaliação do leucograma, lavado broncoalveolar (BAL), celularidade hematopoiética medular e neuroquímica. Os experimentos foram realizados $24 \mathrm{~h}$ após a última sessão de nebulização. $\mathrm{O}$ número de células do $\mathrm{BAL}$ foi significantemente maior nos animais do grupo $\mathrm{EE}$, em relação àqueles dos grupos $\mathrm{CC}$ $(P<0.01), C E(P<0.01)$ e EC $(P<0.001)$. Na contagem diferencial do BAL os linfócitos e macrófagos do grupo $E E$ foram significantemente maiores que em os outros grupos avaliados $(\mathrm{P}<0.05)$. Na contagem diferencial de células no sangue não foram observadas alterações ( $\mathrm{P}>0.05)$ para os linfócitos, neutrófilos, eosinófilos e monócitos; porém, observou-se diferenças significativas $(\mathrm{P}<0.05)$ entre o número de bastonetes dos grupos, sendo maior nos animais do grupo $\mathrm{CC}$ em relação àqueles do grupo EC. O número de células hematopoiéticas da medula óssea foi significantemente $(\mathrm{P}<0.05)$ menor nos animais do grupo $\mathrm{EE}$, em relação àqueles do grupo CC. No córtex pré-frontal, há diferenças significantes na relação Ácido Homovanílico/Dopamina (HVA/DA) $(\mathrm{P}<0.05)$, sendo maior nos animais do grupo $\mathrm{EC}$, em relação àqueles do grupo $\mathrm{CE}$. Em conclusão, o estresse pré-natal levou a modulação de células do sistema imune (SI) dos neonatos, evidenciado após a exposição a estresse agudo pós-natal, amplificando a resposta alérgica pulmonar. Sugere-se que a maior susceptibilidade dos animais do grupo EE seja consequência de alterações induzidas pelo estresse pré-natal no eixo hipotálamo-pituitária-adrenal (HPA).

Palavras-chave: Neuroimunomodulação, estresse pré-natal, asma, modelo murino.

\title{
Resumen
}

Debido a su rápido crecimiento el feto es particularmente vulnerable a los cambios en el ambiente hormonal. Esto sugiere que situaciones adversas de la madre durante la gestación pueden alterar el desarrollo y la salud de la descendencia, principalmente debido a la permeabilidad de la barrera placentaria a diversas hormonas y sustancias. El objetivo del presente trabajo fue estudiar el efecto del estrés prenatal sobre la regulación de la inflamación alérgica pulmonar, empleando el modelo murino de asma experimental. Para este propósito fueron utilizadas ratonas vírgenes de linaje suizo de $50 \mathrm{~d}$ de edad. Fue empleado el modelo de descargas eléctricas en las patas (Footshock) para inducir el estrés prenatal y el modelo de estrés denominado "metro de Nueva York" para el estrés posnatal. Las hembras fueron divididas en 4 grupos experimentales: CC: hembras no estresadas; CE: hembras estresadas posnatalmente a los $60 \mathrm{~d}$ de edad (PND60); EC: hembras nacidas de madres estresadas entre el día 15 (GD15) y 18 de gestación (GD18); EE: hembras nacidas de madres estresadas entre el GD15 y GD18 y estresadas posnatalmente al PND60. La inducción de la inflamación alérgica pulmonar fue realizada a través de la sensibilización de los animales con solución de ovoalbúmina (OVA) $0,1 \mathrm{mg} \mathrm{Kg}^{-1}$ sc. para posteriormente evaluar leucograma, lavado broncoalveolar (BAL), celularidad hematopoyética medular y neuroquímica. Los experimentos fueron realizados 24 horas después de la última sesión de nebulización. El número de células del BAL fue significativamente mayor en los animales del grupo $E E$, en comparación con los del grupo $C C(P<0.01)$, CE $(P<0.01)$ y $C E(P<0.001)$. En el recuento diferencial del $B A L$, los linfocitos y macrófagos del grupo EE fueron significativamente más altos que los otros grupos estudiados $(\mathrm{P}<0.05)$. En el recuento diferencial de células en la sangre no fueron observadas alteraciones $(\mathrm{P}>0.05)$ para los linfocitos, neutrófilos, eosinófilos y monocitos; sin embargo, se observaron diferencias significativas $(\mathrm{P}<0.05)$ entre los grupos en el número de bastonetes, siendo mayor en los animales del grupo CC en relación al grupo EC. El número de células hematopoyéticas de la médula ósea fue significativamente menor $(\mathrm{P}<0.05)$ en los animales del Grupo $\mathrm{EE}$, en comparación con los del grupo de CC. En la corteza prefrontal, hubo diferencias significativas en la relación Ácido Homovanílico/Dopamina (HVA/DA) ( $\mathrm{P}<0.05)$, siendo mayor en los animales del grupo EC, en comparación con los del grupo CE. En conclusión, el estrés prenatal produjo modulación de las células del sistema inmune (SI) de los neonatos, evidenciado después de la exposición a un estrés agudo posnatal, por la amplificación de la respuesta alérgica pulmonar. Se sugiere que la mayor susceptibilidad de los animales del grupo EE sea resultado de los cambios inducidos por el estrés prenatal en el eje hipotálamo-pituitaria-adrenal (HPA).

Palabras clave: Neuroimunomodulación, estrés prenatal, asma, modelo murino.

\begin{abstract}
Due to the rapid growth of the fetus it is particularly vulnerable to insults and changes in hormonal milieu. Therefore, is suggested that adverse situations experienced by the pregnant mother can alter the development and health of offspring, mainly due to the permeability of the placental barrier to various hormones and substances. The aim of the present investigation was to study the effects of prenatal stress in the regulation of pulmonary allergic inflammation, employing the murine model of experimental asthma. For this purpose, were used virgin female mice, Swiss lineage, of 50 days old. The models used were foot shock to induce prenatally stress, and "New York subway" stress to induce postnatally stress. Females were divided into 4 groups: CC group: not stressed females; CE group: postnatally stressed females (PND60); EC: females born from stressed mothers (GD15 to GD18); EE Group: females born from stressed mothers (GD15 to GD18) (footshock) and postnatally stressed (PND60). The induction of allergic pulmonary inflammation was done through sensitization of animals with 0,1 mg. $\mathrm{Kg}^{-1}$ sc of ovalbumin (OVA) solution, to further evaluate leukogram, bronchoalveolar lavage (BAL) hematopoietic marrow cellularity and neurochemistry. The experiments were performed 24 hours after the last session of nebulization.
\end{abstract}

Efeito do estresse pré-natal na regulação da inflamação alérgica pulmonar no modelo murino de asma experimental 
The number of BAL cells was significantly higher in EE group animals compared with the CC group $(\mathrm{P}<0.01), \mathrm{CE}(\mathrm{P}<0.01)$ and $\mathrm{CE}(\mathrm{P}<0.001)$. In the differential count of the $\mathrm{BAL}$, lymphocytes and macrophages of EE group were significantly higher than the other groups studied $(P<0.05)$. In the blood differential cell count were not observed changes $(P>0.05)$ for lymphocytes, neutrophils, eosinophils and monocytes; however, there were significant differences $(P<0.05)$ observed in the number of rods cells between groups, being higher in animals the CC group compared to EC group. The number of hematopoietic cells of the bone marrow was significantly lower $(P<0.05)$ in animals of Group EE, compared with CC group. In the prefrontal cortex, there were significant differences in homovanillic acid /dopamine (HVA/DA) $(\mathrm{P}<0.05)$ rate, being higher in the EC group, compared to EC group. In conclusion, prenatal stress modulated the immune system (SI) cells of neonates, evidenced after exposure to a post-natal acute stress by amplification of pulmonary allergic response. It is suggested that the increased susceptibility of animals EE group is a result of changes induced by prenatal stress on hypothalamus pituitary-adrenal (HPA) axis.

Key words: neuroimmunomodulation, prenatal stress, asthma.

\section{Introducción}

É sabido que o estresse da fêmea durante a gestação pode prejudicar o desenvolvimento de diversos sistemas do filhote. Isto decorre pela permeabilidade da barreira placentária a diversas substâncias produzidas pela mãe, que deste modo atingem o feto e interagem com sistemas de feedback neuroendócrinos fetais (Fonseca e Palermo-Neto, 2005; Entringer et al., 2015).

Estudos prévios evidenciaram que diversos estímulos estressores aplicados nas gestantes podem gerar efeitos de longa duração no desenvolvimento físico, comportamento, regulação do eixo hipotálamo-pituitária-adrenal (HPA), imunocompetência, inflamação das vias aéreas e efeitos adversos na atividade neuronal da prole (Mazur-Kolecka et al., 1996; Palermo-Neto et al., 2001; Fonseca et al., 2002).

O período de desenvolvimento fetal é marcado pelo crescimento e maturação tecidual. Nesta fase acontecem, de forma ubíqua entre as espécies, altas taxas de replicação celular e grande parte da maturação e diferenciação do encéfalo e do sistema imune (SI). Sendo o organismo, portanto, mais profundamente afetado pela atividade e influências ambientais (Saal et al., 1991; Semple et al., 2013).

Tanto em ratos quanto em camundongos, alterações induzidas por estresse materno são mais frequentemente apontadas quando o estresse é aplicado durante o terço final da gestação, período durante o qual há diferenciação das gônadas, trato reprodutivo, órgãos linfoides e formação encefálica. Em camundongos esta fase corresponde do $15^{\circ}$ ao $19^{\circ}$ dia de gestação (Palermo-Neto et al., 2001; Fonseca et al., 2002; Gerardin et al., 2005).

A resposta ao estresse está centrada na atividade do eixo hipotálamo-pituitária- adrenal (HPA), o qual produz glicocorticoide como resultado final. A ligação dos glicocorticoides a receptores (GRs) existentes no hipotálamo e na pituitária inibe a liberação do hormô- nio liberador de corticotrofinas (CRH) e do hormônio adrenocorticotrófico (ACTH), diminuindo em consequência, a secreção do glicocorticoide (McEwen et al., 1997; Melly et al., 1997). Além disso, outras porções do encéfalo, como o sistema límbico e o hipocampo, regulam a atividade do eixo HPA. Estas estruturas respetivamente ativam ou inibem o núcleo paraventricular (PVN) do hipotálamo, regulando a secreção de CRH (Kandel et al., 2014; Kapoor et al., 2008); Neste processo, estudos neurofisiológicos apontam para uma importante participação do córtex pré-frontal (Kandel et al., 2014); por tanto, no presente trabalho foram avaliados neurotransmissores nesta área.

Os mecanismos que esclarecem o efeito do estresse pré-natal no funcionamento do eixo HPA do feto não são totalmente compreendidos; mas acredita-se que parte dos hormônios liberados pela mãe em resposta a um estímulo estressor atravessam a barreira placentária e modificam os circuitos de feedback fetais ainda em desenvolvimento (Weinstock, 2005; Entringer et al. 2015). Estudos com animais tem demostrado que o estresse pré-natal diminui o volume e o numero de receptores glicocorticoides e mineralocorticoides no hipocampo (principal inibidor do eixo HPA), aumentando assim a secreção de glicocorticoide na prole (Glover et al., 2010).

Grande parte da influência do SNC sobre o SI é exercida pelo eixo HPA. O hipotálamo recebe informações da periferia, integra-se com o ambiente interno, e promove o necessário ajuste de certas funções, como o funcionamento do sistema nervoso autônomo simpático e a secreção endócrina (Jacobson, 2005). Pelo fato do hipotálamo ser o centro integrador do SNA e da secreção endócrina durante o estresse, avaliou-se os níveis de neurotransmissores hipotalâmicos.

Uma vez que o sistema imune é multimediado, lesões ou interferências que levem ao prejuízo do mesmo tendem a ser atenuadas ou mesmo compensadas, impedindo a percepção das reais alterações decorrentes 
das mesmas. No entanto, quando o sistema lesado é submetido a um desafio suas deficiências podem então ser detectadas. Foi neste sentido que, neste estudo, escolheu-se como desafio para detectar as possíveis alterações promovidas pelo estresse pré-natal a inflamação alérgica pulmonar num modelo murino de asma experimental.

A asma é uma doença inflamatória crônica das vias aéreas, na qual várias células têm papel fundamental tais como os eosinófilos, mastócitos, neutrófilos, células dendríticas e linfócitos T (Boulet et al., 2015; Ochoa -Amaya et al., 2016).

O cenário inflamatório observado para o desencadeamento da asma pode ser caracterizado, sinteticamente, pela presença pulmonar de mastócitos degranulados, eosinófilos, ativação de linfócitos Th1 e Th2 e geração de citocinas (Tian et al., 2014; De Oliveira et al., 2011; Choy et al., 2015; Ochoa-Amaya et al., 2015).

Contudo, a exposição a um estressor por si só não é capaz de modificar funções imunes de forma a levar aos sintomas asmáticos. O estresse é visto como um processo que, em contrapartida, acentua as respostas inflamatórias e, que é capaz de aumentar a frequência, duração, e a intensidade dos sintomas presentes nas crises asmáticas (Chen e Miller, 2007). De fato, na literatura não há dados que sinalem ação direta de estressores sobre um quadro asmático, mas diversas publicações apontam o papel indireto dos mesmos (Chen e Miller, 2007; Segerstrom, 2004; Marshall e Agarwal, 2000; Portela et al., 2002; Portela et al., 2007).

Especificamente, já foi demonstrado que a exposição pré-natal crônica a estressores imprevisíveis, incrementou significativamente a inflamação alérgeno-induzida das vias aéreas em uma prole de ratas, com maior infiltrado eosinofilico no BAL (Nogueira et al., 1999). A prenhez e a lactação representam modelos experimentais que ilustram como os níveis elevados de corticosterona e as respostas ao estresse diminuídas afetam o sistema imune (Monasterio et al., 2013).

É de amplo conhecimento que os glicocorticoides liberados em consequência de um estímulo estressor são potentes imunomoduladores, sendo capazes de direcionar o balanço Th1/Th2 para uma resposta do tipo Th2 (Del Prete, 1992; Sternberg, 2001) e que corticosteroides maternos são hábeis em cruzar a barreira placentária (Gitau et al., 1998). Logo, a hipótese corrente é de que a excessiva e contínua exposição da prole in útero aos corticoides maternos afetaria o de- senvolvimento do SI e, principalmente, o direcionaria para um padrão Th2.

Neste sentido e, considerando-se o embasamento discutido, é que introduzimos além do estresse prénatal, outro pós-natal para entender estes efeitos sobre o quadro asmático, através da análise da celularidade total e diferencial num modelo murino de asma experimental em camundongas fêmeas.

\section{Materiais e metodos}

\section{Animais}

Foram utilizados camundongas fêmeas virgens da linhagem Swiss, com $50 \mathrm{~d}$ de idade, procedentes do biotério do Departamento de Patologia da Faculdade de Medicina Veterinária e Zootecnia (FMVZ-USP). Os animais permaneceram durante todo o experimento em caixas plásticas medindo $28 \times 17 \times 12 \mathrm{~cm}$, com maravalha esterilizada e isenta de impurezas Os animais foram utilizados seguindo as normas e procedimentos éticos relativos ao uso de animais de laboratório do Comitê de Ética da FMVZ-USP, baseadas naquelas descritas pelo "Comittee on Care and Use of Laboratory Animal Resources, National Research Council, EUA". As caixas foram mantidas em sala com aeração, exaustão, temperatura $\left(22 \pm 2^{\circ} \mathrm{C}\right)$ e umidade $(45 \%-65 \%)$ controladas, em um ciclo claro/escuro de $12 \mathrm{~h}$, com luz ligada às 7:00h; sendo fornecidos aos animais água e ração ad libitum.

\section{Obtenção dos filhotes e formação dos grupos}

As fêmeas foram sincronizadas na fase de anestro do ciclo estral antes do acasalamento (Figura 1). Diariamente entre 07:00 e 09:00 h, realizou-se a observação da presença do tampão vaginal, considerado como indicativo de acasalamento e, por tanto, considerado como o dia zero de gestação (GD0). No dia 10 de gestação (GD10), as fêmeas foram separadas dos respectivos machos e colocadas em caixas individuais, onde permaneceram até o desmame dos filhotes, aos 21 dias de vida (PND21).

Ao desmame, os animais foram separados e pesados, sendo os machos utilizados em outros experimentos, e as fêmeas distribuídas em 4 grupos, cada um dos quais conformado por animais de varias ninhadas, assim:

Grupo CC: fêmeas não estressadas.

Grupo CE: fêmeas estressadas pós-natalmente aos 60 dias de idade (PND60), utilizando o modelo de estresse do metrô de Nova lorque. 


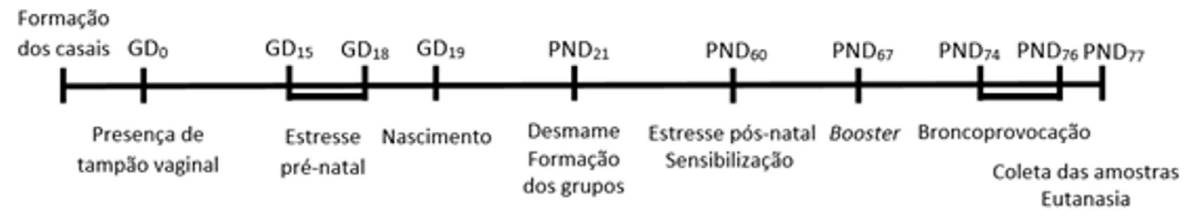

Figura 1. Desenho experimental. GD: Gestational day; PND: Post natal day; BAL: lavado broncoalveolar.

Grupo EC: fêmeas nascidas de mães estressadas entre o dia 15 (GD15) e 18 de gestação (GD18), mediante sessões de choque elétrico nas patas, uma vez ao dia.

Grupo EE: fêmeas nascidas de mães estressadas entre o dia 15 (GD15) e 18 de gestação (GD18), mediante sessões de choque elétrico nas patas, uma vez ao dia e estressadas pós-natalmente, aos 60 dias de idade (PND60), utilizando o modelo de estresse do metrô de Nova lorque.

\section{Modelos de estresse}

\section{Footshock estresse - choques elétricos nas patas}

O aparelho consiste numa caixa de choque metálica (AVS Projetos Especiais - São Paulo, SP, Brasil) com parede frontal em acrilico transparente, medindo $36 \mathrm{x}$ $25 \times 18 \mathrm{~cm}$. Seu piso é constituído de 24 barras metálicas separadas entre si por 1,5 cm; estas se encontram conectadas a um gerador de choques com alternador de polaridade, que permite a seleção da amperagem $(0,2 \mathrm{~mA})$. O fundo da caixa é provido de uma bandeja plástica removível, que coleta as excretas dos animais, situada a $2.5 \mathrm{~cm}$ abaixo das barras. A caixa é acondicionada dentro de um móvel com 80 × 51 × 54 cm, a qual isola aos animais dos estímulos externos.

O número das sessões de choque, tempo de duração, tempo de adaptação do animal à caixa antes do início e o tempo máximo e mínimo entre sessões foram reguladas através de um software (4stressbox - AVS Projetos Especiais) que realiza a interface entre o equipamento e o computador (Pentium II - Microsoft). O modelo de estresse pré-natal empregado foi o de choques intermitentes e inescapáveis, liberados nas patas dos animais. Cada sessão de estresse consistiu em 10 choques, aplicados entre 08:00 e 10:00 h da manhã, com intervalo randômico de 5 a 25 segundos, a fim de evitar-se o condicionamento. Ressalte-se que este modelo vem sendo utilizado com sucesso para avaliações neuroimunes e comportamentais em nossos laboratórios (Palermo-Neto et al. 2001; Fonseca et al., 2002).

\section{Estresse do "Metrô de Nova lorque"}

É um modelo de estresse descrito por Dhabhar e McEwen (1997), cujo laboratório situa-se em Nova lorque (USA), e foi assim denominado por assemelhar-se à situação vivenciada por um indivíduo ao embarcar no metrô em horário de grande circulação de usuários: espaço com restrita capacidade de movimentação do corpo e com agitação contínua.

Consiste na adaptação de um modelo clássico estressor, o "estresse de restrição de movimentos", considerado capaz de promover uma experiência estressante de natureza psicológica, através do sentimento de confinamento do animal. Nesta metodologia, os animais têm seus movimentos restringidos sem serem fisicamente comprimidos e sem experimentarem dor (Dhabhar e McEwen, 1997; Glavin et al., 1994; Berkenbosh et al., 1991). O modelo de restrição é extremamente útil para o estudo dos mecanismos, tanto centrais como periféricos, das desordens relacionadas ao estresse, assim como para o estudo de fármacos para o tratamento destas desordens (Glavin et al., 1994). O aparato de restrição de movimentos consiste de uma placa de madeira laminada $(23,5 \mathrm{~cm}$ de comprimento) onde se fixam 6 tubos de PVC $(3 \mathrm{~cm}$ de diâmetro $\mathrm{x} 10$ $\mathrm{cm}$ de comprimento) para restrição individual, com as extremidades fechadas para evitar escape, mas com orifícios frontais para ventilação e traseiros permitindo a passagem da cauda do animal estressado. Para emprego do "estresse do metrô de $\mathrm{NI}^{\prime}$, o aparato foi colocado sobre um agitador mecânico (Agitador Kline - Nova Ética, Modelo 108, Vargem Grande Paulistana), programado para 1 rotação/segundo. $O$ estresse pos natal foi realizado no PND60 por um período de 2 horas, lembrando-se que durante o mesmo o animal não tinha acesso à água ou ração.

\section{Ovariectomia (OVX)}

As fêmeas foram ovariectomizadas para minimizar as variáveis do experimento, pois é sabido que os hormônios sexuais femininos interferem com o curso da inflamação alérgica pulmonar (Riffo-Vasquez et al., 2007). Os animais foram anestesiados com quetamina (100 
$\mathrm{mg} / \mathrm{kg})$ e xilazina $(20 \mathrm{mg} / \mathrm{kg})$ por via intraperitoneal. Somente fêmeas ovariectomizadas em diestro e com redução da massa uterina foram utilizadas no estudo.

\section{Indução da inflamação alérgica pulmonar}

Sensibilização e broncoprovocação in vivo: as camundongas receberam $10 \mu \mathrm{g}$ ovoalbumina e $10 \mathrm{mg}$ de hidróxido de alumínio, preparadas em $\mathrm{NaCl}$ 0,9\% ou em solução salina (PBS) s.c. Após uma semana (dia 7) os camundongos receberão $10 \mu \mathrm{g}$ de OVA dissolvido em solução salina ou PBS por via s.c. na dose de 0,1 ml.Kg-1 (booster) (Hamasato et al., 2014). Para os animais estressados pós-natalmente o protocolo foi o mesmo, realizado imediatamente após a retirada das fêmeas do aparato estressor. A broncoprovocação foi desencadeada 1 semana após o booster, expondo-se os animais ( 1 vez x por dia por 3 dias consecutivos) à inalação de OVA (1\% em PBS). A sessão de inalação foi realizada por 15 minutos colocando dois animais por sessão em caixa plástica $(18,5 \mathrm{~cm}$ X $18,5 \mathrm{~cm}$ X $13,5 \mathrm{~cm}$ ) acoplada em nebulizador ultrassônico (marca ICEL) com capacidade de produzir névoa com partículas entre 0,5 a $1,0 \mathrm{~m}^{3}$. O período de 14 dias foi escolhido visto que, após a injeção subcutánea de OVA emulsionada em alúmen, os níveis circulantes de imunoglobulinas E (IgE) aumentam rapidamente entre 7 e 14 dias. Os experimentos foram procedidos 24h após a última sessão de nebulização.

\section{Lavado broncoalveolar (BAL)}

As células (mononucleares e polimorfonucleares) presentes no espaço broncoalveolar foram obtidas com a técnica de lavado broncoalveolar (BAL) (Riffo-Vasquez et al., 2007). Para tanto, 24 horas após a broncoprovocação os animais foram anestesiados com ketamina $(100 \mathrm{mg} / \mathrm{kg})$ e xilazina $(20 \mathrm{mg} / \mathrm{kg})$ por via ip, a cavidade peritoneal exposta e realizada o dessangramento por meio da secção da aorta abdominal. Foi feita incisão longitudinal na região cérvico-ventral, a traqueia exposta e canulada utilizando uma cânula de polietileno acoplada a uma seringa de plástico contendo 1,5 $\mathrm{ml}$ de PBS. O BAL obtido foi centrifugado, por 10 minutos a $1500 \mathrm{rpm}$, o sobrenadante desprezado e o botão celular ressuspenso em $1 \mathrm{ml}$ de PBS. A contagem do número total de células foi realizada em câmara hemocitométrica de Neubauer e a contagem diferencial foi feita por microscopia óptica e contadas no mínimo 200 células, diferenciando-as segundo o tipo celular (macrófagos, linfócitos, neutrófilos e eosinófilos).

Alíquotas da amostra $(90 \mu \mathrm{l})$ acrescidas de $10 \mu \mathrm{l}$ de cristal violeta $0,2 \%$ dissolvido em ácido acético (30\%) foram utilizadas. Para a contagem diferencial das células, alíquotas da amostra $(100 \mu \mathrm{l})$ foram colocadas em Citospin (Fanem) e centrifugadas a $1.000 \mathrm{rpm}$ por 5 minutos. As lâminas obtidas foram coradas pelo método de May-Grünwald-Guimsa modificado (Hamasato et al., 2014). Ao final do lavado foram retirados fragmentos do pulmão para análise histológica.

\section{Leucograma (total e diferencial)}

Alíquotas de sangue heparinizadas foram coletadas por punção cardíaca e, após, $10 \mu \mathrm{l}$ de sangue foram diluídos em $190 \mu \mathrm{L}$ de líquido de Türk ao 3\%, e contagem total foi realizada em câmara de Neubauer. A contagem diferencial dos leucócitos circulantes foi realizada e corada pelo método May-Grünwald-Giemsa modificado a seguir contadas 100 células (Hamasato et al., 2014).

\section{Contagem Total de Células Hematopoiéticas Medulares}

Os animais foram submetidos a eutanásia como descrito anteriormente. $\mathrm{O}$ fêmur esquerdo foi retirado e com o auxílio de uma pinça sustenido, e mantido sobre um tubo Falcon $(50 \mathrm{ml})$; em seguida o canal medular foi perfundido com PBS $(5 \mathrm{ml})$ utilizando uma seringa plástica. A suspensão medular obtida foi homogeneizada com o auxílio de uma pipeta automática de $5 \mathrm{ml}$ e centrifugada a $1.500 \mathrm{rpm}$ por $10 \mathrm{~min}$. $\mathrm{O}$ sobrenadante foi desprezado e as células ressuspensas em $1 \mathrm{ml}$ de PBS.

A contagem total de células foi realizada em câmara de Neubauer. Para tanto, uma alíquota da amostra (90 ul) foi acrescida de $10 \mu \mathrm{l}$ de cristal violeta $(0,2 \%)$ dissolvido em ácido acético (30\%), totalizando, portanto, uma diluição de 1:10. Os resultados foram expressos em número de células $\times 10^{6} / \mathrm{ml}$ (Hamasato et al., 2014).

\section{Dosagem de Neurotransmissores}

Os animais destinados para este experimento foram decapitados em guilhotina. O encéfalo foi retirado, lavado com solução salina gelada $\left(4^{\circ} \mathrm{C}\right)$ e as duas estruturas pré-escolhidas, o hipotálamo e o córtex frontal, foram coletados sobre placa de gelo seco, dissecadas com base nas coordenadas de Paxinos e Watson (1988).

O estudo da neuroquímica foi realizado com o fim da determinação das concentrações de neurotransmissores e de seus metabólitos nos cérebros dos animais: Dopamina (DA), ácido homovanílico (HVA), ácido 3, 4-dihidroxifenilacético (DOPAC); relação HVA/DA, relação DOPAC/DA; Serotonina (5HT), ácido 5-hidroxindo- 
lacético (5HIAA), relação 5HIAA/5HT, Noradrenalina (NOR), ácido 3-metoxi-4-hidroximandélico (VMA) e a relação VMA/NOR. Para tal, o hipotálamo e o córtex frontal foram preparados para posterior análise por sistema de cromatografia líquida de alta eficiência (HPLC). O método foi previamente descrito no laboratório (Felicio et al., 1996).

Para as dosagens neuroquímicas, o sistema utilizado foi o de cromatografia líquida de alta eficiência (HPLC) (Shimatzu, Kyoto, JP). A técnica utilizada foi a de cromatografia em fase reversa com pareamento iônico, a qual se fundamenta na cromatografia de partição ou absorção (Gerenutti, 1996).

\section{Análise estatística}

Os resultados obtidos foram analisados pelo teste de Bartlet, para verificação de homocedasticidade. Os dados paramétricos foram analisados com ANOVA de uma via seguida e os não paramétricos pelo Teste de Kruskal-Wallis, seguidos ou não por testes post-hoc. Os dados obtidos foram apresentados sob a forma de média \pm erro padrão médio (SEM), sendo que o nível de significância crítico admitido foi de até $5 \%(p<0.05)$ para todas as análises realizadas.

\section{Resultados}

\section{Efeitos do estresse pré e (ou) pós-natal no lavado broncoalveolar (BAL) e na análise histopatológica qualitativa pulmonar}

Foram empregadas 43 camundongas fêmeas, ovariectomizadas, provenientes de 12 ninhadas/grupo. A ANOVA indicou a existência de diferenças significantes no número total de células do BAL de camundongas expostas ou não ao estresse pré e (ou) pós natal $(\mathrm{P}<0.0007)$. O teste post hoc indicou que o número de células do BAL foi significantemente maior nos animais do grupo $E E$ em relação àqueles dos grupos $C C$ $(\mathrm{P}<0.01), \mathrm{CE}(\mathrm{P}<0.01)$ e EC $(\mathrm{P}<0.001)$ (Figura 2A e 2B).

Todas as fotomicrografias foram realizadas a partir do lobo pulmonar inferior direito, coletado sempre imediatamente após o BAL. As amostras, depois de fixadas em formaldeído $4 \%$ foram processadas e coradas pelo método de Hematoxilina - Eosina ( $\mathrm{H}-\mathrm{E})$.

\section{Efeitos do estresse pré e (ou) pós-natal no leucograma total e diferencial}

Os mesmos animais do experimento anterior foram empregados neste experimento. A ANOVA indicou diferenças significantes no número de células totais do sangue $(\mathrm{P}<0.01)$. O teste de Dunn indicou que os valores do grupo $\mathrm{CE}$ foram significantemente maiores que do grupo EE (Figura 4A). Na contagem diferencial de células não foram observadas alterações $(P>0.05)$ para os linfócitos, neutrófilos, eosinófilos e monócitos; porem, observou-se diferenças significativas $(\mathrm{P}<0.05)$ entre o número de bastonetes dos grupos; o teste post hoc indicou que o número destas células (bastonetes) foi maior nos animais do grupo $\mathrm{CC}$ em relação àqueles do grupo EC (Figura 4B) na contagem diferencial.

\section{Efeitos do estresse pré e (ou) pós-natal na contagem total de células hematopoiéticas da medula óssea}

Os mesmos animais empregados no experimento anterior foram utilizados neste experimento. A ANOVA
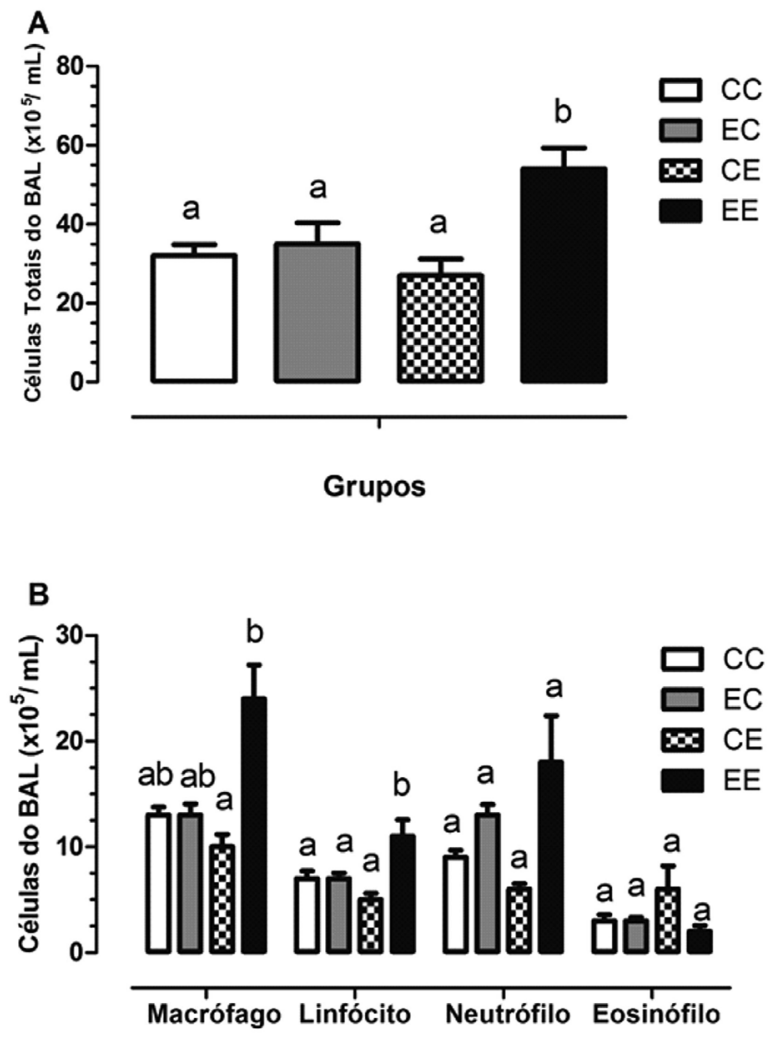

Figura 2. Efeitos do estresse pré e (ou) pós-natal no BAL de camundongas ovariectomizadas e sensibilizadas com OVA. CC- grupo controle não estressado; EC - grupo controle estressado pré-natalmente; $\mathrm{CE}$ - grupo controle estressado pós-natalmente; EE - grupo experimental estressado pré e pós-natalmente. Anova seguida por Kruskal-Wallis. ${ }^{a, b}$ Barras com letras não iguais são diferentes $(P<0.05)$ 
indicou diferenças entre os grupos $(\mathrm{P}<0.05)$. O teste post hoc mostrou que o número de células foi significantemente menor nos animais do grupo $\mathrm{EE}$, em relação àqueles do grupo CC (Figura 5).

\section{Efeitos do estresse pré e (ou) pós-natal nos níveis de neurotransmissores e metabólitos do córtex pré frontal e do hipotálamo}

Foram empregadas 41 camundongas fêmeas ovariectomizadas, provenientes de 12 ninhadas/grupo. As tabelas 1 e 2 mostram os resultados obtidos na avaliação dos níveis de neurotransmissores e metabólitos, respectivamente, do córtex pré-frontal e do hipotálamo.

\section{Neuroquímica}

No córtex pré-frontal, a ANOVA indicou a existência de diferenças significantes na relação HVA/DA $(\mathrm{P}<0.05)$. O teste pos hoc mostrou que a relação entre o metabólito e neurotransmissor foi maior nos animais do grupo EC em relação àqueles do grupo CE. Esta mesma análise não mostrou diferenças entre os níveis dos diferentes grupos (DA, P>0.05; DOPAC, P>0.05; HVA, $P>0.05)$. Nesta mesma área, a ANOVA não indicou a existência de diferenças significantes $(\mathrm{P}>0.05)$ entre os níveis de serotonina, 5-HIAA e na relação 5HIAA/5HT. Mesmos resultados foram obtidos para a noradrenalina e seu metabólito VMA.

No hipotálamo a ANOVA não indicou diferenças ( $\mathrm{P}>0.05)$ entre os diferentes neurotransmissores, metabólitos e relações entre metabólitos e neurotransmissores.

\section{Discussão}

Os resultados do presente trabalho mostram aumento significante de leucócitos e da contagem absoluta de linfócitos e macrófagos no BAL dos animais estressados pré e pós-natalmente (EE) em comparação com os demais grupos estudados (CC, EC e CE). Diminuição significante do leucograma do sangue periférico dos animais do grupo EE em comparação com o grupo CE. Diminuição significante do número total de células hematopoiéticas medulares nos animais do grupo EE em relação àqueles do grupo $\mathrm{CC}$, provavelmente pela maior migração celular ao pulmão, pois foi o grupo que maior inflamação alérgica pulmonar apresentou. No córtex frontal não foram detectadas alterações nos níveis de neurotransmissores e metabólitos da DA, 5HT e NOR. A relação entre o metabólito e neurotransmis-

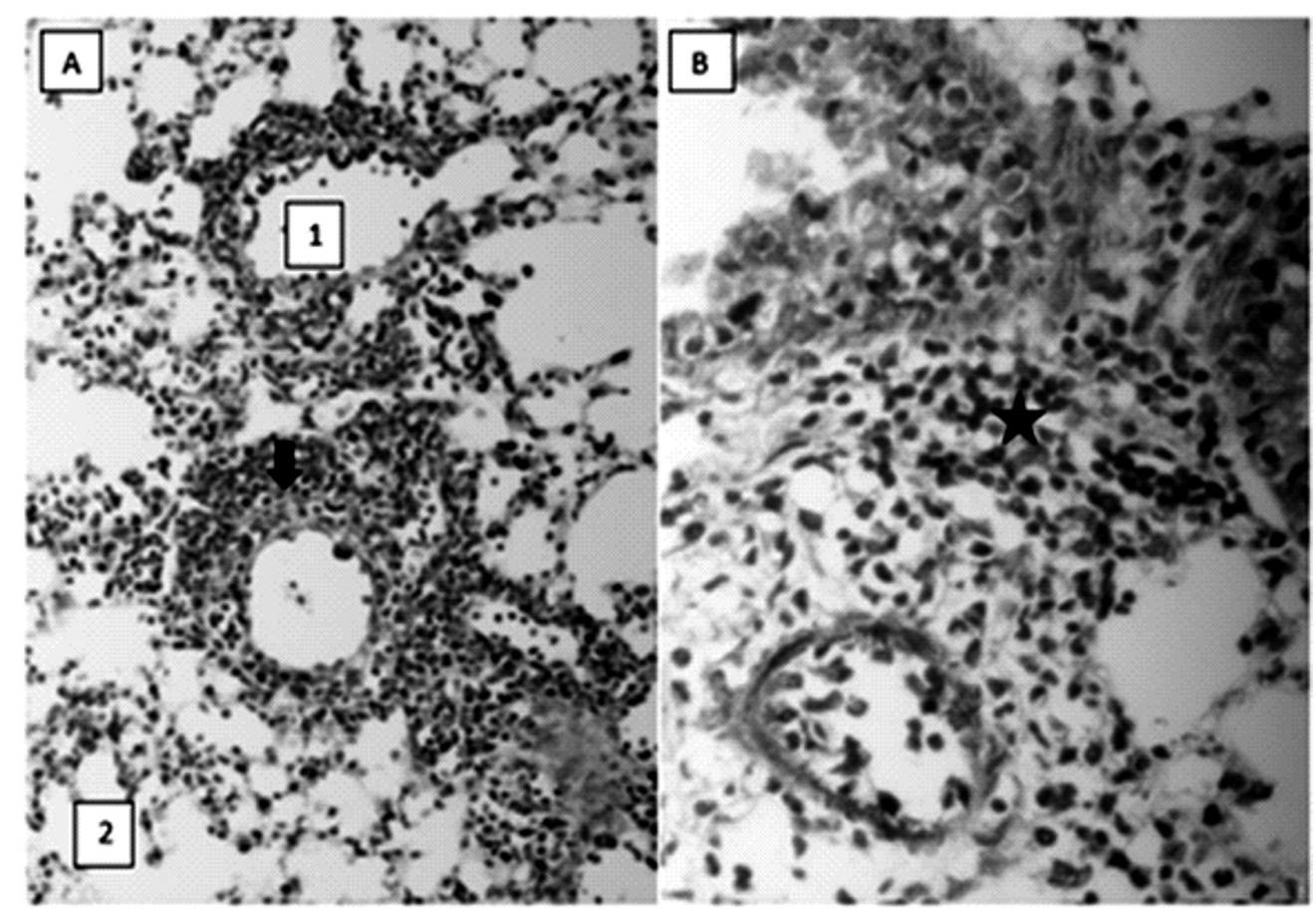

Figura 3. (A) Corte histológico de pulmão (200X-H-E), onde evidencia-se bronquíolos (1) e alvéolos (2) de animal induzido à asma experimental (OVA), com maciça infiltração leucocitária ( ) (B) Corte histológico de pulmão (400x - H-E), de animal induzido à asma experimental (OVA), com maciça infiltração leucocitária, inclusive, nota-se a presença de eosinófilos ( ). 
sor HVA/DA foi maior nos animais do grupo EC em relação àqueles do grupo CE.

Fonseca e Palermo-Neto, (2005), mostraram que o estresse por choque nas patas administrado no mesmo período que neste trabalho, produziu respostas comportamentais compatíveis com aumento de ansiedade paralelas a um maior nível plasmático de corticosterona, caracterizando uma situação de estresse. No entanto, os efeitos no sistema imune foram pouco evidentes (Fonseca e Palermo-Neto, 2005), parecendo que apenas o estímulo pré-natal não foi suficiente para expressar as interferências no SI. Trabalho prévio, com os mesmos grupos experimentais (CC, CE, EC, EE), e também utilizando o modelo de footshock, mostrou que aos 37 dias de vida, apenas animais do grupo CE apresentavam redução do percentual de espraiamento de macrófagos peritoneais previamente ativados por inoculação i.p. de onco-BGC. Nessa ocasião, não se relataram alterações nos demais parâmetros (índice de fagocitose ou produção de óxido nítrico) ou quaisquer mudanças de atividade nas células provenientes dos demais grupos. Já quando avaliada a produção de peróxido de hidrogênio, observou-se redução da concentração da mesma nos animais do grupo CE e aumento naqueles do grupo EE (Fonseca et al., 2002).

Estes dados sugeriram inaptidão do modelo de estresse pré-natal empregado. Como argumento, testamos em um outro trabalho realizado em nosso grupo de pesquisa uma comparação entre os estressores pósnatalmente empregados de footshock stress com o modelo de estresse do metrô de Nova lorque. Os dados deste experimento evidenciaram que, de fato, de algum modo e (ou) em algum grau, o modelo de choques nas patas pareceu não ser efetivo em os animais estudados (camundongos Swiss). Ainda, foi devido ao fato do estresse do metrô de NI apresentar resultados similares aos descritos por seus autores, como robusta redistribuição de leucócitos do sangue periférico para órgãos linfóides como baço e modificações nas contagens de células hematopoéticas medulares (Dhabhar e McEwen, 1997).

Contudo, não descartamos a possibilidade de tratarse de uma linhagem cujas características genotípicas não isogênicas derivem tais resultados, uma vez que apresentam maiores desvios padrões que por vezes mascaram resultados apresentados por outras linhagens. Uma outra hipótese plausível advém do fato que evolutivamente muitas fêmeas experimentam estressores durante a gestação. Deste modo, visto pelo foco da seleção natural Darwiniana, parece haver uma contradição a isto a interpretação de que estressores são sempre deletérios. Logo, argumentamos a existência
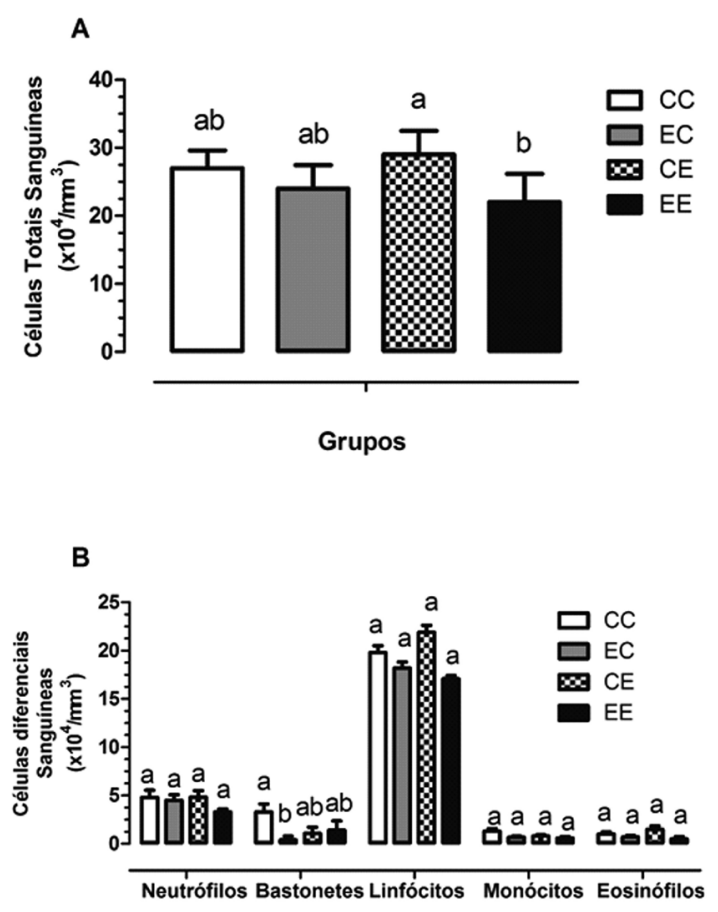

Figura 4 Efeitos do estresse pré e (ou) pós-natal no número de leucócitos circulantes (leucograma total e diferencial) de camundongas ovariectomizadas e sensibilizadas com OVA. CC: grupo controle não estressado; EC: grupo controle estressado pré-natalmente; CE: grupo controle estressado pós- natalmente; EE: grupo experimental estressado pré e pós-natalmente. ${ }^{a, b}$ Barras com letras não iguais são diferentes $(\mathrm{P}<0.05)$.

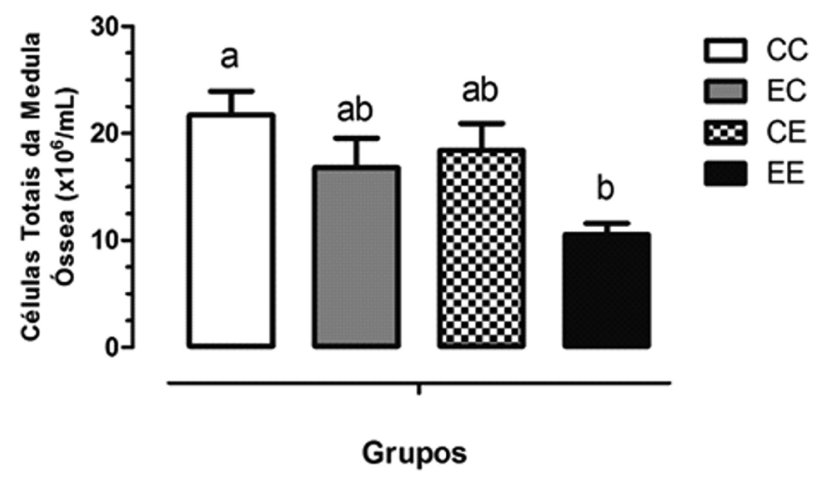

Figura 5. Efeitos do estresse pré e (ou) pós-natal na contagem total de células hematopoiéticas medulares de camundongas ovariectomizadas e sensibilizadas com OVA. CC: grupo controle não estressado; EC: grupo controle estressado pré-natalmente; CE: grupo controle estressado pós-natalmente; EE: grupo experimental estressado pré e pós-natalmente. ANOVA seguida pelo teste de Dunnet. ${ }^{a, b}$ Barras com letras não iguais são diferentes $(P<0.05)$. 
de sistemas de redundância orgânica, o que inibiria a efetividade do estressor pré-natal frente aos parâmetros avaliados.

Especificamente, considere-se que todos os parâmetros avaliados decorrem de leucócitos e que parte especialmente relevante da resposta ao estressor decorre da liberação de catecolaminas. De fato, estudos recentes demonstram que todos os leucócitos aparentemente expressam 2AR, com exceção apenas dos subclones do tipo Th2 CD4+. Sabe-se, porém, que mesmo estas células Th2 CD4+, são reguladas por estímulos adrenérgicos via liberação de citocinas em decorrência da sensibilização pelas catecolaminas das células que contém os 2AR (Kohm et al., 2000).

Sustentando esta hipótese, encontramos uma publicação de 2003 na Brain, Behavior and Immunity, que detalha o perfil imunológico de um camundongo nocaute de 2AR que, ao contrário das expectativas dos autores, não apresentou diferenças em quaisquer dos parâmetros avaliados em relação aos animais do grupo controle: peso corporal; peso relativo de baço, timo, ou linfonodos; celularidade total ou fenotipagem de baço, timo, linfonodos ou medula óssea; produção de anticorpos primários e secundários frente à imunização (medido por até 11 semanas); avidez por lgG; etc. Segundo os autores, mecanismos de compensação in vivo teriam causado esse efeito, sem envolver upregulation de outros receptores adrenérgicos.

Já em relação à inflamação alérgica pulmonar, os dados obtidos no presente trabalho sugerem que, a exposição ao estressor pós-natal, e apenas quando concomitante com a exposição ao estressor pré-natal (grupo EE), propiciou um aumento estatisticamente significante do numero de leucócitos observados no BAL, em comparação às femeas dos demais grupos (CC, EC e CE). Este dado, por sua vez, apresentou correlação direta com a redução significante de leucócitos observados na medula óssea e no sangue circulante dos animais, o que explica ter havido uma liberação de células medulares hematopoéticas e, também, uma maciça redistribuição destas células oriundas do sangue periférico para o compartimento pulmonar.

Na asma, diversos autores sugerem a implicação de estressores como fatores para desencadeamento ou agravamento da inflamação alérgica pulmonar, sejam eles pré-natais (Oliveira et al., 2008; Jiang et al., 2015; Holt, 1999; Nogueira et al., 1999) ou pós-natais (Chen e Miller, 2007; Tillie-Leblond et al., 2005; Ligeiro-Oliveira et al., 2004). Contudo, segundo Chen e Miller (2007), há um paradoxo teórico na discussão do paradigma estresse-asma. Como já dito, as principais vias de responsividade a estressores são o eixo HPA e o SNAS, ou seja, a liberação de glicocorticóiodes e de adrenalina e noradrenalina. Assim, num contexto de asma, teríamos, ao menos, teoricamente: altos níveis de corticóides que atuariam inibindo o processo inflamatório (Nagata et al., 1999) e também uma ativação adrenérgica que atuaria gerando broncodilatação (receptores $\beta 2$ adrenérgicos) (Ochoa-Amaya et al., 2016), isso tem sido demostrado que os níveis de noradrenalina são aumentados, entanto que os de adrenalina ficam em valores normais durante a asma moderada aguda no homem (Nagata et al., 1999).

Nesse sentido, os glicocorticóides e análogos da adrenalina com ação $\beta 2$ adrenoceptores são aplicados na clínica como fármacos usados no tratamento sintomático da asma (anticorpos - IgE), que passam a orquestrar a resposta típica à asma (Chen e Miller, 2007; Segerstrom, 2004). No entanto, a estimulação induzida pelos agonistas dos receptores $\beta 2 \mathrm{AR}$ expressada pelos linfócitos residentes no pulmão pode exercer tanto uma influência benéfica ou prejudicial sobre a resposta alérgica. Por exemplo, se a estimulação $\beta 2 A R$ dos linfócitos B pela NA aumenta a produção de IgE, com a consequente degranulação dos mastócitos, aumentando deste modo a liberação da histamina e a intensidade da resposta alérgica pulmonar (Kohm et al., 2000).

A contra-argumentação disto no sentido de correlação positiva do paradigma estresse-asma advém de publicações recentes que sugerem que pode haver dessenbilização ou down-regulation dos receptores que são ativados pelos hormônios do estresse após a exposição repetida aos estressores, fato que, por sua vez, culminaria na potenciação dos quadros asmáticos (Chen e Miller., 2007). Neste contexto, parece que as arrestinas (moléculas que se ligam intracelularmente à proteína G) são as principais responsáveis pela diminuição de receptores à membrana celular e, portanto, potenciação do quadro asmático. Uma vez que o GPCR (receptor acoplado à prot. G) é ativado, desencadeia-se uma cascata de eventos bioquímicos que culminam na ligação intracelular de -arrestina ao receptor e, este evento acarreta a internalização do mesmo (Hislop, 2005).

No caso específico da asma, publicações recentes descrevem que as -arrestinas estão vinculadas aos receptores 2-adrenérgicos, ou seja, há internalização destes receptores e, por conseguinte, menor capacidade à broncodilatação mediados pela via adrenérgica (Premont e Gainetdinov, 2007). 
Tabela 1. Efeitos do estresse pré e (ou) pós-natal nos níveis $(\mathrm{ng} / \mathrm{mL})$ de neurotransmissores e seus metabólitos do córtex préfrontal de camundongas ovariectomizadas e sensibilizadas com OVA. CC: grupo controle não estressado; EC: grupo controle estressado pré-natalmente; CE: grupo controle estressado pós-natalmente; EE: grupo experimental estressado pré e pósnatalmente. São apresentadas as médias e respectivos erros-padrão.a- diferente $(P<0.05)$ do grupo CC, ANOVA seguida pelo teste de Kruskal Walis. a em relação ao grupo EC.

\begin{tabular}{|l|c|c|c|c|}
\hline & CC & EC & CE & EE \\
\hline DA & $497,9 \pm 59,2$ & $494,6 \pm 71,0$ & $559,6 \pm 46,3$ a & $435,4 \pm 21,8$ \\
\hline HVA & $234,0 \pm 22,2$ & $286,9 \pm 65,9$ & $227,2 \pm 24,8$ & $194,0 \pm 21,3$ \\
\hline DOPAC & $263,2 \pm 22,1$ & $253,4 \pm 38,3$ & $286,8 \pm 24,5$ & $262,7 \pm 8,7$ \\
\hline HVA/DA & $0,51 \pm 0,1$ & $0,53 \pm 0,1$ & $0,44 \pm 0,1$ & $0,43 \pm 0,1$ \\
\hline DOPAC/DA & $0,56 \pm 0,1$ & $0,49 \pm 0,1$ & $0,55 \pm 0,1$ & $0,55 \pm 0,1$ \\
\hline $5 H T$ & $1791,8 \pm 134,6$ & $1629,3 \pm 274,0$ & $1643,5 \pm 5,3$ & $1700,0 \pm 111,8$ \\
\hline $5 H I A A$ & $1933,9 \pm 110,1$ & $1932,2 \pm 174,4$ & $2151,4 \pm 105,2$ & $1961,4 \pm 118,1$ \\
\hline $5 H I A A / 5 H T$ & $1,11 \pm 0,1$ & $1,20 \pm 0,2$ & $1,36 \pm 0,1$ & $1,20 \pm 0,1$ \\
\hline NOR & $1448,9 \pm 118,8$ & $1591,6 \pm 159,2$ & $1564,9 \pm 139,5$ & $1595,5 \pm 115,4$ \\
\hline VMA & $833,4 \pm 48,7$ & $762,6 \pm 76,7$ & $891,7 \pm 45,4$ & $841,5 \pm 35,5$ \\
\hline VMA/NOR & $0,59 \pm 0,1$ & $0,57 \pm 0,1$ & $0,60 \pm 0,1$ & $0,54 \pm 0,1$ \\
\hline
\end{tabular}

Tabela 2. Efeitos do estresse pré e/ou pós-natal nos níveis $(\mathrm{ng} / \mathrm{mL})$ de neurotransmissores e metabólitos hipotalâmicos de camundongas ovariectomizadas e sensibilizadas com OVA. CC- grupo controle não estressado; EC - grupo controle estressado pré-natalmente; $C E$ - grupo controle estressado pós-natalmente; $E E$ - grupo experimental estressado pré e pós-natalmente. Anova seguida pelo teste de Kruskal Walis. São apresentadas as médias e respectivos erros-padrão.

\begin{tabular}{|l|c|c|c|c|}
\hline & CC & EC & CE & EE \\
\hline DA & $3467,6 \pm 350,4$ & $2832,9 \pm 527,1$ & $3141,4 \pm 331,4$ & $2136,6 \pm 275,4$ \\
\hline HVA & $503,1 \pm 38,4$ & $434,6 \pm 65,9$ & $391,1 \pm 35,0$ & $316,1 \pm 40,9$ \\
\hline DOPAC & $564,0 \pm 48,1$ & $535,7 \pm 80,4$ & $506,7 \pm 35,6$ & $400,0 \pm 50,5$ \\
\hline HVA/DA & $0,15 \pm 0,01$ & $0,16 \pm 0,01$ & $0,13 \pm 0,01^{\mathrm{a}}$ & $0,15 \pm 0,01$ \\
\hline DOPAC/DA & $0,17 \pm 0,01$ & $0,20 \pm 0,01$ & $0,17 \pm 0,01$ & $0,19 \pm 0,01$ \\
\hline 5 HT & $1121,1 \pm 75,9$ & $1070,7 \pm 110,0$ & $1245,3 \pm 137,8$ & $1000,6 \pm 70,0$ \\
\hline 5 HIAA & $1265,2 \pm 104,4$ & $1229,5 \pm 180,6$ & $1144,7 \pm 57,8$ & $1029,7 \pm 46,8$ \\
\hline $5 H I A A / 5 H T$ & $1,14 \pm 0,1$ & $1,19 \pm 0,1$ & $1,02 \pm 0,1$ & $1,05 \pm 0,1$ \\
\hline NOR & $330,1 \pm 41,3$ & $332,2 \pm 50,8$ & $349,0 \pm 27,4$ & $342,6 \pm 17,5$ \\
\hline VMA & $1092,8 \pm 67,5$ & $1090,0 \pm 112,2$ & $1265,5 \pm 124,7$ & $1163,6 \pm 42,3$ \\
\hline VMA/NOR & $3,6 \pm 0,4$ & $3,7 \pm 0,6$ & $3,3 \pm 0,2$ & $3,4 \pm 0,2$ \\
\hline
\end{tabular}


A questão é que os resultados dos estudos experimentais e clínicos sobre alterações imunes subsequentes à exposição a fatores estressores não são conclusivos. A resposta a fatores estressores agudos pode levar a uma certa ativação imunológica, em concentrações fisiológicas os GC inibem respostas Th1 e aumentem respostas Th2 (Sternberg, 2001), enquanto outros encontraram decréscimo da mesma, com diminuição na função e no número de células NK (Kiecolt e Glaser, 1988; Lazzarini et al., 2001). Neste sentido, a ativação do eixo HPA e consequente liberação de corticoides, levaria a redução da inflamação pulmonar pela ação anti-inflamatória já conhecida deste hormônio explicando a redução do número de células do BAL. Assim, a corticosterona endógena pode aumentar a resposta patofisiológica da adrenal a proteger o pulmão, ainda que é insuficiente para suprimir a inflamação alérgica pulmonar (Nagata et al., 1999).

Neste trabalho, verificou-se no grupo de camundongos fêmeas EE menor número de células do SI no sangue e naquelas da medula, evidenciando maior migração de células do SI da medula para o pulmão. Desta forma, pode-se concluir que o estresse pré-natal levou a prejuízos no sistema imune dos neonatos que foram evidenciados quando da exposição a um estresse agudo pós-natal. No caso, estes animais tornaram-se mais susceptíveis a resposta inflamatória pulmonar promovida pela exposição à OVA.

Neste sentido, a redução das células do SI no sangue ocorreu de maneira uniforme, ou seja, houve contribuição de todas as células e não de alguma em particular, o que se comprova pela análise diferencial dos leucócitos do sangue periférico e do BAL. Deste modo, a avaliação dos dados de leucograma total aferido no BAL e no sangue periférico mencionados, poderiam sugerir que os estressores pré e pós-natais atuaram de forma a agravar o quadro asmático.

É certo que um incremento de glóbulos brancos nos espaços pulmonares, como o observado nas fêmeas do grupo EE, corrobora para uma amplificação sintomática da inflamação alérgica pulmonar. Isto porque, além de propiciar o congestionamento das vias aéreas, têm potencial para prover maior síntese e liberação das moléculas envolvidas na quimiotaxia de mais leucócitos para o local inflamado e também, de citocinas e quimicionas tipicamente inflamatórias.

Assim sendo, sabe-se que o estresse pode levar as alterações no SI através da ativação do sistema nervoso e do sistema endócrino (Ader et al., 1995; Biondi e Zannino, 1997). O mecanismo da comunicação entre o
SI e o sistema nervoso ocorre por duas vias: o sistema nervoso autônomo (SNA) e o eixo HPA.

O SNA enerva os órgãos do SI (nódulos linfáticos, medula óssea, timo, baço e tecidos linfoides) e o eixo HPA, por sua vez, libera neurotransmissores e hormônios que regulam a atividade dos diversos órgãos e células envolvidos na resposta imunológica (Sternberg, 2001). Fonseca e Palermo-Neto (2005) mostraram que o mesmo estresse pré-natal aumentou os níveis de corticosterona na prole feminina de camundongos, evidenciando papel importante do eixo HPA. Além disto, são descritos receptores de membrana biologicamente ativos para diversos neurotransmissores e hormônios em células do sistema imune (Ader et al., 1995). Sabe-se que existem diversas moléculas envolvidas na intercomunicação entre os sistemas, como catecolaminas (liberadas pela medula adrenal, pelo SNC e o SNA), encefalinas, substância $P$, neuropeptídeo $Y$, glicocorticoides do eixo HPA, prolactina, hormônio luteinizante (LH), hormônio do crescimento $(\mathrm{GH})$, hormônio folículo-estimulante (FSH), hormônio liberador de gonadotrofina $(\mathrm{GnRH})$, hormônio corticotrófico (CRH), hormônio liberador de tirotropina (TRH), adrenocorticotrófico $(\mathrm{ACTH})$, fator de liberação de corticotropina (CRF) e ß-endorfinas, citocinas, etc. (Maier et al., 1998; Sternberg, 2001). A ativação do SNS em resposta ao estresse aumenta os níveis plasmáticos de catecolaminas. As catecolaminas mudam a atividade celular imune a través da proteína $\mathrm{G}$ acoplada aos receptores $\beta$ adrenérgicos (Hamasato et al., 2014).

Os resultados deste estudo não mostraram alterações quer seja nos níveis ou na relação neurotransmissor/ metabólito de Noradrenalina tanto no córtex pré-frontal como no hipotálamo, sugerindo que, neste caso, a maior susceptibilidade dos animais do grupo EE seja consequência de alterações induzidas pelo estresse pré-natal no eixo HPA.

\section{Referencias}

Ader R, Cohen N, Felten D. Psychoneuroimmunology: interactions system and the immune system. The Lancet. 1995;345: 99-103.

Berkenbosh F, Wolvers D, Derijk R. Stress exposure and immunization Radioimmunoassays (RIAs) CRF antiserum protocol and. Journal of Steroidal Biochemistry and Molecular Biology. 1991;40(4): 639-647.

Biondi M, Zannino LG. Psychological Stress, Neuroimmunomodulation, and Susceptibility to Infectious Diseases in Animals and Man: A Review. Psychotherapy and Psychosomatics. 1997;66(1):3-26.

Boulet LP, FitzGerald JM, Reddel HK. The revised 2014 GINA strategy report: opportunities for change. Current opinion in pulmonary medicine. 2015;21(1): 1-7. 
Chen E, Miller GE. Stress and inflammation in exacerbations of asthma. Brain, Behavior, and Immunity. 2007;21(8):993-999.

Choy DF, Choy DF, Hart KM, Borthwick LA, Shikotra A, Nagarkar $\mathrm{DR}$, et al. TH2 and TH17 inflammatory pathways are reciprocaIly regulated in asthma. 2015;7(301):301-.

Dhabhar FS, McEwen BS. Acute stress enhances while chronic stress suppresses cell-mediated immunity in vivo: a potential role for leukocyte trafficking. Brain, behavior and immunity. 1997;11(4):286-306.

Entringer S, Buss C, Wadhwa PD. Prenatal stress, development, health and disease risk: A psychobiological perspective-2015 Curt Richter Award Paper. Psychoneuroendocrinology. 2015;62:366-375.

Felicio LF, Florio JC, Sider LH, Cruz-Casallas PE, Bridges RS. Reproductive experience increases striatal and hypothalamic dopamine levels in pregnant rats. Brain Research Bulletin, 1996;40(4):253-256.

Fonseca ESM, Palermo-Neto J. 2005. Participação do sistema opioidérgico e dos glicocorticóides nas alterações comportamentais. Universidade de São Paulo.

Fonseca ESM, Massoco CO, Palermo-Neto J. Effects of prenatal stress on stress-induced changes in behavior and macrophage activity of mice. Stress. 2002;124(5):954-960.

Gerardin DCC, Pereira OC, Kempinas WG, Florio JC, Moreira EG, Bernardi MM. Sexual behavior, neuroendocrine, and neurochemical aspects in male rats exposed prenatally to stress. Physiology and Behavior. 2005; 84(1):97-104.

Gitau R, Cameron A, Fisk NM, Glover V. Fetal exposure to maternal cortisol. The Lancet. 1998;352(9129):707-708.

Glavin GB, Paré WP, Sandbak T, Bakke HK, Murison R. Restraint stress in biomedical research: An update. Neuroscience \& Biobehavioral Reviews. 1994;18(2):223-249.

Glover V, O'Connor TG, O'Donnell K. Prenatal stress and the programming of the HPA axis. Neuroscience and Biobehavioral Reviews. 2010;35(1):17-22.

Hamasato EK, de Lima AP, de Oliveira AP, dos Santos Franco AL, de Lima WT, Palermo-Neto J. 2014. Cohabitation with a sick partner increases allergic lung inflammatory response in mice. Brain, Behavior, and Immunity: 1-9.

Hislop A. Developmental biology of the pulmonary circulation. Paediatric Respiratory Reviews. 2005;6(1):35-43.

Holt PG. Potential role of environmental factors in the etiology and pathogenesis of atopy: a working model. Environ Health Perspect, 1999;107 Suppl: 485-487.

Jacobson L. Hypothalamic-pituitary-adrenocortical axis regulation. Endocrinology and Metabolism Clinics of North America. 2005;34(2):271-292.

Jeffrery PK. The development of large and small airways. American Journal of Respiratory and Critical Care Medicine. 1988;157(5):S174-S180.
Jiang CL, Liu L, Li Z, Buttgereit F. The novel strategy of glucocorticoid drug development via targeting nongenomic mechanisms. Steroids. 2015;102:27-31.

Kajekar R. Environmental factors and developmental outcomes in the lung. Pharmacology and Therapeutics. 2007;114(2):129145.

Kandel E, Hyman S, Cohen J. 2014. Transtornos do humor e ansiedade. In McGraw-Hill, ed. Princípios de Neurociências: 12221240.

Kandel E, LeDoux J, Damasio A. 2014. Emoções e sentimentos. Princípios de Neurociências. McGraw-Hill: 940-947.

Kapoor A, Petropoulos S, Matthews SG. Fetal programming of hypothalamic-pituitary-adrenal (HPA) axis function and behavior by synthetic glucocorticoids. Brain Research Reviews. 2008;57(2):586-595.

Kiecolt JK, Glaser R. Methodological Issues in Behavioral with Humans ' Immunology. Brain, Behavior and immunity. 1988;2:67-78.

Kohm AP, Kohm AP, Tang Y, Sanders VM, Jones SB. Activation of antigen-specific CD4+ Th2 cells and B cells in vivo increases norepinephrine release in the spleen and bone marrow. Journal of Immunology. 2000;165(2):725-733.

Kotecha S. Lung growth: implications for the newborn infant. Archives of disease in childhood. Fetal and neonatal edition. 2000;82(1):69-74.

Lazzarini R, Palermo-Neto J, Malucelli BE. Reduction of Acute inflammation in Rats by Diazepam: Role of Peripheral Benzodiazepine Receptors and Corticosterone. Immunopharmacology and Immunotoxicology. 2001;23(2):253-265.

Ligeiro-Oliveira AP, Fialho de Araújo AM, Lazzarini R, Silva ZL, De Nucci G, Muscará MN, Tavares de Lima W, PalermoNeto J. Effects of amphetamine on immune-mediated lung inflammatory response in rats. Neuroimmunomodulation. 2004;11(3):181-190.

Maier SF, Watkins LR, Maier F. Cytokines for Psychologists: Implications of Bidirectional Immune-to- Brain Communication for Understanding Behavior, Mood, and Cognition. Psychological Review. 1998;105:83-107.

Marshall GD, Agarwal SK. Stress, immune regulation, and immunity: applications for asthma. Allergy and asthma proceedings : the official journal of regional and state allergy societies. 2000;21(4):241-246.

Mazur-Kolecka B, Kubera M, Skowron-Cendrzak, A., Basta-Kaim, A., Shani, J., Effect of prenatal stress on ontogenesis of immunoregulatory cell maturation in mice. Polish Journal of Pharmacology, 1996;48(6):621-625.

McEwen BS, Biron CA, Brunson KW, Bulloch K, Chambers WH, Dhabhar FS, Goldfarb RH, Kitson RP, Miller AH, Spencer RL, Weiss JM. The role of adrenocorticoids as modulators of immune function in health and disease: Neural, endocrine and immune interactions. Brain Research Reviews. 1997;23(1-2): 79-133.

Melly S, Oitzl AD, Van-Haarst ER. Behavioral and neuroendocrine responses controlled by the concerted action of central minera- 
locorticoid (MRS) and glucocorticoid receptors (GRS). Psychoneuroendrocrinology. 1997;22(Supplement 1):87-93.

Monasterio N, Vergara E, Morales T. Hormonal influences on neuroimmune responses in the CNS of females. Frontiers in Integrative Neuroscience, 2013;7(January):8.

Nagata A, Yamada Y, Nakamura A, Asano T, Yamada T, Isaka M, Itoh M. Alteration of endogenous corticosteroids and catecholamines in allergen- induced eosinophilic inflammation in Brown Norway rats. Allergology International. 1999;48(3):209-215.

Nogueira PJ, Ferreira HH, Antunes E, Teixeira NA. Chronic mild prenatal stress exacerbates the allergen-induced airway inflammation in rats. Mediators of inflammation. 1999;8(2):119-122.

Ochoa-Amaya JE, Marino LP, Tobaruela CN, Namazu LB, Calefi AS, Margatho $\mathrm{R}$, et al. Attenuated allergic inflammatory response in the lungs during lactation. Life Sciences. 2016;151:281-287.

Ochoa-Amaya JE, Hamasato EK, Tobaruela CN, Queiroz-Hazarbassanov N, Anselmo Franci JA, Palermo-Neto J, et al. Short-term hyperprolactinemia decreases allergic inflammatory response of the lungs. Life sciences. 2015;142: 66-75.

Oliveira APL, Lino-Dos-Santos-Franco A, Hamasato EK, QuinteiroFilho W, Hebeda CB, Damazo AS, et al. Amphetamine modulates cellular recruitment and airway reactivity in a rat model of allergic lung inflammation. Toxicology Letters. 2011;200(12):117-123.

Oliveira APL, Ligeiro de Oliveiraa AP, Lazzarinib R, Cavriania G, Quinteiro-Filhob WM, Tavares de Limaa W, Palermo-Netob J. Effects of single or repeated amphetamine treatment and withdrawal on lung allergic inflammation in rats. International Imunopharmacology. 2008;8(9):1164-1171.

Palermo-Neto J, Massoco CO, Favare RC. Effects of maternal stress on anxiety levels, macrophage activity, and Ehrlich tumor growth. Neurotoxicol Teratol. 2001;23(5):497-507.

Paxinos G. Watson, C., 1988. The Rat Brain in Stereotaxic Coordinates, 4th ed. CD-ROM. G. Paxinos \& C. Watson, eds., San Diexgo, California.

Portela CDP,Tibério IF, Leick-Maldonado EA, Martins MA, Palermo-Neto J. Effects of diazepam and stress on lung inflammatory response in OVA-sensitized rats. American journal of physiology. Lung cellular and molecular physiology. 2002;282(6):1289-1295.
Portela CP, Leick-Maldonado EA, Kasahara DI, Prado CM, CalvoTibério IF, Martins MA, Palermo-Neto J. Effects of stress and neuropeptides on airway responses in ovalbumin-sensitized rats. NeurolmmunoModulation. 2007;14(2): 105-111.

Premont RT, Gainetdinov RR. Physiological roles of G protein-coupled receptor kinases and arrestins. Annual review of physiology. 2007;69:511-534.

Del Prete G. Human Th1 and Th2 lymphocytes: their role in the pathophysiology of atopy. Allergy. 1992;47(5):450-455.

Riffo-Vasquez Y, A. P. Ligeiro de Oliveira AP, Page CP, Spina D, Tavares-de-Lima $W$. Role of sex hormones in allergic inflammation in mice. Clinical and Experimental Allergy. 2007;37(3):459-470.

Saal FS, Even MD, Quadagno DM. Effects of maternal stress on puberty, fertility and aggressive behavior of female mice from different intrauterine positions. Physiology \& Behavior. 1991;49(6):1073-1078.

Segerstrom SC. Psychological Stress and the Human Immune System: A Meta- Analytic Study of 30 Years of Inquiry. Psychol ogy Bulletin. 2004;130(4):601-630.

Semple BD, Blomgren K, Gimlin K, Ferriero DM, Noble-Haeusslein $\mathrm{LJ}$. Brain development in rodents and humans: Identifying benchmarks of maturation and vulnerability to injury across species. Progress in Neurobiology. 2013;106(107):1-16.

Sternberg EM. Eurosterone meeting. Neuroendocrine regulation of autoimmune / inflammatory disease. Journal of Endocrinology. 2001;169:429-435.

Tian WM, Yang YG, Shang YX, Cai XX, Chen WW, Zhang H. Role of 1,25-dihydroxyvitamin D 3 in the treatment of asthma. European Review for Medical and Pharmacological Sciences. 2014;18:1762-1769.

Tillie-Leblond I, Gosset P, Tonnel AB. Inflammatory events in severe acute asthma. Allergy: European Journal of Allergy and Clinical Immunology. 2005;60(1): 23-29.

Weinstock M. The potential influence of maternal stress hormones on development and mental health of the offspring. Brain, Behavior and Immunity. 2005;19(4): 296-308. 